
\title{
25 Research Sourere \\ Effect of Untreated Oil Palm Fruit Fibre on the Engineering Properties of Road Construction Earth Materials
}

Chidozie Maduabuchukwu Nwakaire ( $\nabla$ cm.nwakaire@unizik.edu )

Nnamdi Azikiwe University https://orcid.org/0000-0003-0961-9849

Ukomadu Chidebele Evaristus

Teesside University Middlesbrough, United Kingdom

Onu Chijioke Elijah

Nnamdi Azikiwe University, Awka, Nigeria

\section{Research}

Keywords: California bearing ratio, compaction, density, laterites, moisture content, Oil palm fruit fibre

Posted Date: June 30th, 2020

DOI: https://doi.org/10.21203/rs.3.rs-38664/v1

License: (c) (i) This work is licensed under a Creative Commons Attribution 4.0 International License.

Read Full License 


\section{Abstract}

This study first evaluated the engineering properties of lateritic soil samples from three selected locations in South Eastern Nigeria (Nawfia, Okpuno, and Ugwuoba). The effect of Oil Palm Fruit Fibre (OPFF) on the properties of these soil materials was investigated, with special emphasis on road construction applicability. The samples were subjected to different tests to ascertain their index properties. Varying proportions of OPFF from $0.5 \%$ to $3 \%$ were incorporated into the soil samples and the effects were observed based on compaction and California Bearing Ratio (CBR) results. The control samples without inclusion of OPFF achieved the highest Maximum Dry Densities (MDD), the MDDs reduced linearly as the OPFF content increased. Consequently, the CBR values decreased with increase in OPFF. The reduction in MDD for the Nawfia samples ranged from $0.29 \%$ to $5.31 \%$ as the OPFF increased from $0.5 \%$ to $3 \%$. The MDD of the Okpuno sample also reduced within the range of $1.25 \%$ to $9.51 \%$ whereas the reduction for the Ugwuoba soil is within the range of $1.55 \%$ and $9.79 \%$. With the inclusion of the OPFF, there was up to $75 \%$ to $83 \%$ drop in CBR values of the soil rendering them very unsuitable for pavement subgrade. It was concluded that the presence of fibre depreciated the engineering properties of the earth materials. Direct application of OPFF in any part of road pavement has been dissuaded.

\subsection{Introduction}

Weak soils are often encountered in road construction sites. Some of these locations are avoided based on the reconnaissance report, but after the highway route location, some points of soft and collapsible soils may still be encountered (Nwakaire et al., 2016). Many factors contribute to the weakness of the soils. Some are natural whereas some are artificial. Whichever be the case, such soils are considered unsuitable for pavement construction (Winter and Wong, 2020). In places where they are encountered as the natural soils, they are either removed and substituted with a borrowed subgrade material or improved by addition of some stabilising materials (Han, 2014).

There are many methods of soil improvements which has been found effective over the years. The use of binders like cement and lime has been mostly applied for pavement materials (Yao et al., 2016; Horpibulsuk et al., 2011). However, due to the high level of environmental impacts associated with the use of these binders, many researchers have made concerted efforts towards discovering alternative soil improvement methods (Sargent et al., 2016; Zhang et al., 2013). The use of some waste materials for soil stabilisation promises to be a viable alternative.

The quest for improved sustainability in waste management is an ever growing one (Plati, 2019). Sustainable waste management involves reuse and recycling of such wastes instead of disposal of the wastes in landfills (Mahmoud et al., 2012). Neglecting these sustainability objectives has increased the carbon footprint of many industries and also resulted in different forms of environmental degradations (Ossa et al., 2016). The oil palm tree (Elaeis guineensis) is a widely grown economic tree in most parts of Africa and many parts of Asian continent. The oil palm is a unique evergreen tree that grows on a single stem bearing its fruits in bunches of various weights and fruit counts. Ibitoye and Onie (2013) and 
Jagustyn et al. (2013) estimated that a typical palm fruit bunch would weigh about $25 \mathrm{~kg}$ and contain about 1000 palm fruits. The primary product of oil palm fruit processing is the palm oil. Indonesia, Malaysia, Thailand, Colombia, and Nigeria are the world leading countries in oil palm plantation and palm oil productions (Anyaoha et al., 2018). As a result of high rate of palm oil production, much waste is generated. This is because the oil milling process leads to generation of huge amounts of several byproducts which can be disposed as wastes (Sreekala et al., 2001). Inefficient disposal of these fibres can lead to eutrophication and other environmental challenges. Rickson et al. (2015) submitted that such organic waste can improve soil fertility but the use of OPFF for this purpose is quite low as there are many alternative biodegradable and processed manures and fertilizers. As a result of this, these wastes are not properly utilized and are already constituting land fill problems in areas where palm oil is produced. OPFF is one of the major waste products after fresh palm oil fruit has been processed. If this fibre improves the CBR values of the soil, its application as soil reinforcement would be useful for soil improvement and solid waste reduction.

In some rural localities in Nigeria, these fibres are dried and burnt for cooking. This use consistently reduced in recent years, making fibres to constitute landfill and environmental challenges. OPFF is predominantly the mesocarp and endocarp fibre containing some particles of the palm kernel shell. Though some of these fibres are used as fuel in the palm oil mills for boiling of the effluents, yet a very larger proportion of the wastes are produced than needed by each mill (Anyaoha et al., 2018).. Disposal of such amounts of wastes becomes an issue of critical concern to various stakeholders. This is because, at present, there is a greater awareness that landfills are filling up, resources are being used up, the planet is being polluted and that non-renewable resources would get exhausted. There is a need to discover more environmentally friendly materials. That is why there have been many experimental investigations and a great deal of interest has been created worldwide on potential applications of natural fibres for soil reinforcement in recent years. Rowell et al. (2000) submitted that some factors contribute to the performance of natural fibres. These factors include the age of the plant, method of fibre production, and part of the plant from which the fibre was isolated. Fibre reinforcement has been considered in projects relating to slope stabilization, embankment construction, subgrade stabilization, and stabilization of thin surfaces such as landfill covers.

Fibres are known to have high tensile strength and a fibre reinforced soil is expected to exhibit high shear strength and resistance to tensile loads (Li \& Ding, 2002). Otoko et al. (2016) investigated the effectiveness of using oil palm fibre ash in soft soil stabilization. Their study focused on improving the properties of chikoko soil located in the Niger Delta area of Nigeria. The palm wastes were first burnt and the ash blended with the soil. The study recommended an addition of $5 \%$ lime by weight of the soil in order to maximise the stabilisation performance of the ash. The soil sample with $5 \%$ lime and $3 \%$ palm ash resulted in about $7 \%$ increase in unsoaked CBR values of the soil and about $32 \%$ increase in 23 hour soaked CBR of the soil. Basically, the ash was used as a substitute for lime stabilisation. Another study by Otoko and Ephraim (2014) considered the environmental impact of burning the fibres to obtain the ash and attempted to investigate into the performance of the fibres as reinforcements in the soil. They soaked the fibre reinforced lateritic soils in water and allowed to swell; and thereafter, air dried in the laboratory. 
Cracks were observed and unconfined compressive strength measured. They reported that the palm fibre reinforcement worsened the swelling characteristics of the lateritic soil as the volume change was directly proportional to the fibre content, because of the alteration in soil permeability. However, when the reinforced soils were dried increases in compressive strength, elasticity modulus, and ultimate strain were recorded. In view of these uncertainties, there remains a need for more investigations on the behaviour of soil materials with OPFF inclusion, especially as it applies to road construction. This study, therefore, was aimed at investigating into the effect of OPFF on the geo-mechanical properties of soil materials used for road construction. OPFF has a very low density and as a result, smaller proportions by weight were blended with the soil samples. Apart from revealing the effects of this fibre inclusion, the suitability of the lateritic soil samples gotten from the three borrow pits were also observed and reported. This is very expedient for ensuring effective waste management without compromising the quality assurance of road pavement constructions (Igwe \& Umbugadu, 2020).

\subsection{Materials And Methods}

\subsection{Materials}

Two materials used for this study are lateritic soils and oil palm fruit fibre. Lateritic soils are often encountered as road pavement subgrade and also mostly used for road pavement subbase in most parts of Nigeria. In South Eastern Nigeria, there are many sites with abundance of laterites used for road construction. These sites are referred to as borrow pits. Lateritic soils used in this study were collected from three different borrow pits in South East Nigeria. They are Okpuno, Nawfia and Ugwuoga borrow pits. The oil palm fruit fibre was obtained from Enugu-ukwu palm oil processing plant located in Anambra State, South Eastern Nigeria. Figure 1 illustrates the procedure of generation of palm oil fruit fibre in the oil palm plant. The fibre comprises of pressed palm oil pericarp with some particles of oil palm fruit shells as shown in Fig. 2. Both the lateritic soils and fibre were air dried before the experiments. The fibres were added to the lateritic soils at different proportions by weight, ranging from 0.5 to $3 \%$ by weight of the laterites.

\subsection{Laboratory Tests}

The experimental methods and procedures adopted for this study are summarised in this section. They include the basic tests required for the quality control of earth materials used for road construction. The tests include; particle size distribution, Atterberg's limits, specific gravity, compaction, and California Bearing Ratio (CBR). The procedures and methods for these tests are described in BS1377. The soils were classified using the Unified Soil Classification System (USCS) and the ASHTO soil classification system.

The compaction tests were performed to determine the relationship between the moisture contents and the dry densities of the soils. In this study, three compaction test methods were adopted and they include; British Standard Light (BSL), the West African Standard (WAS), and the British Standard Heavy (BSH) methods of compaction. The BSL method involves energy derived from a $2.5 \mathrm{~kg}$ rammer falling through a height of $300 \mathrm{~mm}$. The soil samples were divided into three layers with 27 blows per layer. The WAS 
method involves energy derived from a $4.5 \mathrm{~kg}$ rammer falling through a height of $450 \mathrm{~mm}$. The soil samples were divided into five layers with 10 blows per layer. The BSH method involves effort derived from a $4.5 \mathrm{~kg}$ rammer falling at through a height of $450 \mathrm{~mm}$. the soil samples are divided into five layers with 27 blows per layer. A compaction mould of $1000 \mathrm{~cm}^{3}$ volume was used for all the experiments.

The CBR test was carried out to evaluate the bearing capacity of the soil samples. The construction of road pavement requires a regulatory minimum California Bearing Ratio which should not be less than $80 \%$ and $30 \%$ for sub-base materials respectively. The materials were subjected to soaking for 48 hours before testing in order to depict the behaviour of the soil under the worst conditions of rainy seasons. Figure 3 is a typical CBR testing machine.

\subsection{Results And Discussion}

The results of the tests conducted on the soil samples with and without OPFF are presented and discussed in this section. These results have been discussed based on the behavior of the materials as subgrade materials.

\subsection{Grain size analysis}

The particle size distribution analysis was conducted on the soil samples to determine their grading and suitability for pavement construction. Figure 4 shows the curves for the grain size analysis for the three samples.

The particle size analysis for the 3 lateritic samples shows that the cumulative percent retained on No. 200 BS sieve $(0.075 \mathrm{~mm})$ were in the range of $74.64 \%$ and $86.03 \%$. It was observed from the sieve analysis that the Ugwuoba sample has the highest amount of sand (86.03\%), next to Nawfia $(75.87 \%)$ and least is Okpuno (74.64\%). The cumulative percentages passing on No. 200 BS sieve are in the range of $13.97-25.36 \%$, with Okpuno having the highest amount of fines (silt and clay) as $25.36 \%$, next to Nawfia which has $24.13 \%$ of fines and the least is Ugwuoba with $13.97 \%$ of fines. Based on these fine contents, the lateritic soils are suitable for pavement subgrades even in their stabilised state (Bello \& Adegoke, 2010). This is in accordance with the Federal Ministry of Works and Housing (FMWH, 1997) specification which recommends samples with less than $35 \%$ fines as suitable subgrade materials. Consequently, the Ugwuoba soil is the most suitable with regards to this.

From the curves, it can be seen that all three samples have no $D_{10}$ (particle size such that $10 \%$ of the size is finer than this size). $D_{50}$ for all 3 soil samples range from $0.21-0.25$. For Ugwuoba soil samples, $50 \%$ of the particles are larger than 0.25 and $50 \%$ is less than 0.25 . For Okpuno soil sample, $50 \%$ of the particle sizes are larger than 0.25 , and $50 \%$ are less than 0.25 . While for Nawfia soil sample, $50 \%$ of the particle sizes are larger than 0.21 , and $50 \%$ are less than 0.21

\subsection{Consistency limits}


The Atterberg's Limits tests were conducted on the three soil samples used for this experiment. Figure 5 shows the plots for determination of the liquid limits for the three soil samples. The moisture content corresponding to 25 blows is reported as the liquid limits. The difference between the liquid limits and plastic limits gives the plasticity indices of the soils as shown in Fig. 6.

The plasticity indices of the soils are; $10.82 \%$ (Okpuno), 8.92\% (Nawfia) and 2.75\% (Ugwuoba). These are within the $55 \%$ maximum limit set by FMWH for subgrades and fill materials. The value of plasticity indices gives an idea on the amount of clay content contained in a soil sample. The plasticity increases with increase in the fine content of the soil. The presence of fines influence the consistency of the soil. Highly plastic soils are not desirable as they are prone to mud pumping and heaving. Granular materials are more stable for engineering applications.

\subsection{Soil classification}

According to the USCS, the soil samples may be classified as thus; since all the soils have more than $50 \%$ of the soil retained on No. 200 BS sieve, the soils are coarse grained, and the soils are identified as sand (since more than $50 \%$ of the coarse grained fraction pass No. 4 sieve $(4.75 \mathrm{~mm})$. Also since Okpuno and Nawfia samples have plasticity indices greater than $7 \%$, they are referred to as inorganic clays with slight to medium plasticity and group name SC (silty clays). Ugwuoba soil sample has plastic index less than 4 and is classified as inorganic silts with no plasticity and group name SM (silty sands)

According to AASHTO, all the soil samples are granular materials since they all have $35 \%$ or less of the soil passing through No. 200 BS sieve $(0.075 \mathrm{~mm}$ aperture). All soil samples are classified under A-2 since they all have a maximum of $35 \%$ passing $0.075 \mathrm{~mm}$ sieve. Nawfia and Ugwuoba soil samples are classified as A-2-4 since they have plasticity indices less than $10 \%$ and liquid limits less than $40 \%$.

Okpuno soil sample falls in to group A-2-6 since it has liquid limit value less than $40 \%$ and plasticity index above $11 \%$.

\subsection{Compaction of the soils}

The compaction tests were performed to determine the Maximum Dry Density (MDD) and Optimum Moisture Content (OMC) for each of the soil samples. Three compaction efforts were adopted, the BSH, WAS, and BSL. The curves are presented in Fig. 7, Fig. 8, and Fig. 9 for Ugwuoba, Okpuno, and Nawfia samples respectively.

For the three soil samples, the BSH compaction gave the highest value of MDD, followed by WAS, then BSL was the least. The Ugwuoba sample achieved MDD of $2080 \mathrm{~kg} / \mathrm{m}^{3}$ for BSH, $2002 \mathrm{~kg} / \mathrm{m}^{3}$ for WAS, and $1940 \mathrm{~kg} / \mathrm{m}^{3}$ for BSL. The OMCs were $9.5 \%, 9.5 \%$, and $10.2 \%$ for BSH, WAS, and BSL respectively. The Okpuno sample achieved MDD of $2076 \mathrm{~kg} / \mathrm{m}^{3}$ for BSH, $1983 \mathrm{~kg} / \mathrm{m}^{3}$ for WAS, and $1905 \mathrm{~kg} / \mathrm{m}^{3}$ for BSL. The OMCs for this sample are $11.8 \%, 12.7 \%$, and $13 \%$ for BSH, WAS, and BSL respectively. The Nawfia sample achieved MDD of $1884 \mathrm{~kg} / \mathrm{m}^{3}$ for BSH, $1792 \mathrm{~kg} / \mathrm{m}^{3}$ for WAS, and $1750 \mathrm{~kg} / \mathrm{m}^{3}$ for BSL. The OMCs are $14 \%, 14.2 \%$ and $15 \%$ for BSH, WAS, and BSL respectively. Generally, higher compaction energies achieved higher MDD and lesser OMCs. This is because higher compaction energies less amount of 
water to achieve the necessary densification of the soils (Nwakaire et al., 2015). The compaction energies were computed in accordance with Eq. 1 and a plot of their relationship with MDD is shown in Fig. 10. It is a clear indication that compaction plays a key role in densifying and strengthening engineering soils. For this reason, compaction is an important aspect of earthworks in road construction.

Compaction energy (CE) $=\frac{b \times l \times w \times h \times g}{V}$.

Where $b=$ number of blows; $\mathrm{I}=$ number of layers; $w$ = weight of the rammer $(\mathrm{kg}), \mathrm{h}=$ height of fall $(\mathrm{m}), \mathrm{g}=$ acceleration due to gravity $\left(9.81 \mathrm{~m} / \mathrm{s}^{2}\right)$, and $\mathrm{V}=$ volume of the mould. Based on Eq. 1, the CEs for BSL, WAS, and $\mathrm{BSH}$ are $0.60 \mathrm{MN} / \mathrm{m}^{3}, 1.0 \mathrm{MN} / \mathrm{m}^{3}$, and $2.7 \mathrm{MN} / \mathrm{m}^{3}$ respectively.

As compaction energies increase, the MDD also increased. The BSH with the highest compaction energy achieved the highest densification of the soil. This is also the situation in actual practice, the weight of the compactor, intensity of the compaction, and rate of compaction both play important roles in ensuring effective pavement material densification for proper performance.

\subsection{California Bearing Ratio (CBR)}

The results of the CBR conducted for the three soil samples without inclusion of OPFF are reported in Table 1, together with the summary of other index properties already discussed. The highest CBR was recorded for the Ugwuoba soil sample (24\%), next to the Okpuno soil sample (6\%) and is least for the Nawfia sample (4\%). The index properties of these soil samples are summarised in Table 1 . They are soil materials with different geo-mechanical properties and satisfactory subgrade parameters. They were found to be suitable for this study as the objective is to monitor the improvements or reductions in these geo-mechanical properties of theses soils with the inclusion of OPFF. 
Table 1

Index and compaction properties of the natural soils

\begin{tabular}{|llll|}
\hline SOIL SAMPLES & UGWUOBA & OKPUNO & NAWFIA \\
\hline Liquid Limit (\%) & 16.6 & 32.8 & 30.2 \\
\hline Plastic Limit (\%) & 13.85 & 21.98 & 21.291 \\
\hline Plasticity Index (\%) & 2.75 & 10.82 & 8.91 \\
\hline Plasticity & Non plastic & Slightly plastic & Slightly plastic \\
\hline Sand (\%) & 86.03 & 74.64 & 75.87 \\
\hline Silt+ Clay (\%) & 13.97 & 25.36 & 24.13 \\
\hline COLOUR & Reddish brown & Reddish brown & Reddish brown \\
\hline Coeff. Of Uniformity (Cu) & NIL & NIL & NIL \\
\hline Coeff. Of Curvature (Cc) & NIL & NIL & NIL \\
\hline AASHTO Classification & A-2-6 & A-2-6 & A-2-4 \\
\hline USCS Classification system & SM & SC & SC \\
\hline Specific Gravity & 2.60 & 2.57 & 2.55 \\
\hline MDD BSL (Kg/m ${ }^{3}$ ) & 1940 & 1905 & 1750 \\
\hline OMC BSL (\%) & 10.2 & 13 & 15 \\
\hline MDD BSH (Kg/m ${ }^{3}$ ) & 2080 & 2076 & 1884 \\
\hline OMC BSH (\%) & 9.5 & 11.8 & 14.2 \\
\hline MDD WAS (Kg/m ${ }^{3}$ ) & 2002 & 1980 & POOR \\
\hline OMC WAS (\%) & 9.4 & 6.7 & \\
\hline CBR (48 hours. soaked) (\%) & 24 & FAIR & 1792 \\
\hline General rating as subgrade & EXCELLENT & & 14 \\
\hline
\end{tabular}

The CBR is the major discriminating parameter for pavement construction materials. However, all the physical properties are included in Table one for a quick evaluation of how these properties influence the CBR of the soil. In a nutshell, soils with higher specific gravities and MDD are expected to achieve higher CBR. The minimum requirements for 48 hours soaking by the FMWH specification for different layers of a road pavement are listed in Table 2. 
Table 2

Specifications for road pavement materials (FMWH, 1997)

\begin{tabular}{|lll|}
\hline S/NO. & Pavement structural component & Minimum values of CBR (\%) \\
\hline 1 & Base course (natural or unstabilized soil material) & 80 \\
\hline 2 & Base course (cement stabilized soil) & 180 \\
\hline 3 & Sub- base & 30 \\
\hline 4 & Subgrade and/or foundation soil & 5 \\
\hline
\end{tabular}

Part of the project aim lies in estimating the effect of OPFF on subgrade soil of a pavement, hence the project centres around the subgrade. Comparing the values of the CBR gotten form the experiment conducted and the minimum values of the CBR for subgrade as specified by the FMWH, it can be deduced that the soil sample gotten from Ugwuoba and Okpuno borrow pits satisfy the minimum requirements and are thus suitable for use as subgrade material. Whereas, the soil sample gotten from the Nawfia laterite does not meet the minimum requirements and would therefore require stabilization. Nevertheless, how the incorporation of the OPFF will affect the compaction properties and CBR of the three samples were investigated and reported in the next section of this paper.

\subsection{Effect of OPFF on the compaction of the soil samples}

Compaction was carried out on the three soil samples with varying inclusion OPFF within the range of 0$3 \%$. The following results were gotten from the compaction experiments. One compaction energy was used to ensure uniformity of the results gotten. The BSL was chosen because of its lesser compaction energy. It would introduce the least effect from compaction and elaborate more on the effect of OPFF inclusion. Figure 11-13 show the results of the compaction tests with OPFF inclusion.

From the figures it can be observed that the MDD decreases and OMC increases with increasing percentage of oil palm fruit fibre (OPFF). The reduction in MDD for the Nawfia samples ranged from $0.29-5.31 \%$ as the OPFF increased from $0.5-3 \%$. The MDD of the Okpuno sample also reduced within the range of $1.25-9.51 \%$ whereas the reduction for the Ugwuoba soil is within the range of $1.55 \%$ and $9.79 \%$. The trend for the three soils suggest that higher inclusion of the OPFF will lead to a much higher reduction in MDD. The reason can be traced to the fact that MDD depends on the physical properties of the material. The specific gravity of the material affects their density. Yusoff (2010) gave the range of specific gravity for OPFF as 1.2-1.45. This is significantly less than the specific gravity of the soil. More so, the fibres are biodegradable in nature. They were not stiff enough to provide additional rigidity to the soil samples. The MDDs decreased linearly with increase in OPFF as shown in Fig. 14. Consequently, the OMC of the samples increased with increase in OPFF as shown in Fig. 15.

\subsection{Effect of OPFF on California Bearing Ratio of the soils}

The results of the CBR experiments are presented in Fig. 16. Inclusion of OPFF reduces the value of the CBR after 48 hours soaking. 
From these results, there was a remarkable drop in CBR values. The reduction was very significant that the soils could become unsuitable as subgrade or fill material. With up to $1 \%$ OPFF, the CBR tends to zero. The Federal Ministry of Works specification (FMWH, 1997) state that the minimum values of CBR for subgrade in a highway pavement is $5 \%$. It was observed that the Ugwuoba soil sample failed to meet this requirement when the OPFF percentage was in excess of $1.8 \%$. This means that above $1.8 \%$ inclusion of the fibre, the Ugwuoba soil sample was no longer suitable for use as a subgrade material. Also, the Okpuno soil sample failed to meet this criterion when OPFF in percentages as little as $0.22 \%$ was added to the soil. This means that at percentage as little as $0.22 \%$ of the fibre, the Okpuno soil sample was no longer suitable for use as a subgrade material. This sends a very important signal, that instead of considering the fibre from oil palm seed pericarp as a stabilising material, it is best to be considered a deleterious material which should be cleared from any site before compaction is commenced. Since the fibre is biodegradable, it could have some potential feasible reuse alternative in the agricultural industry. However, in line with previous studies, OPFF can be burnt to ash in an electric kiln. The ash which is pozolanic in nature can bring about significant improvement in soil properties (Otoko et al., 2016). Mahato et al. (1993) also described a form of chemical treatment for OPFF to stiffen the fibre before incorporation into soil for improvement of properties. Suroso et al (2013) reported that a combination of OPFF and cement can improve the geotechnical properties of weak soils. This report suggests that the improvement must have been as a result of the cement stabilisation since the OPFF alone failed to exhibit any form of soil improvement potential based on the observations from this study.

\subsection{Conclusion}

The properties of three lateritic soil samples were investigated and analysed in this study. The soils were collected from borrow pits located in Ugwuoba, Okpuno, and Nawfia all located within South-East Nigeria. Their behaviour under compaction and CBR tests when mixed with different proportion of OPFF was reported. The result reveals that the geotechnical properties of the soil samples was affected by differences in compaction energies, compaction moisture content, and amount of OPFF.

The BSH with the highest compaction energy of $2.7 \mathrm{MN} / \mathrm{m}^{3}$ achieved the best compaction for all the samples. The control samples without inclusion of OPFF achieved the highest MDDs for all the samples, the MDDs reduced linearly as the OPFF content increased. Consequently, the CBR values decreased with increase in OPFF. This was as a result of the low density and high water absorption of the OPFF. The 48 hour soaked CBR was adopted for this experiment and in accordance to the findings of Otoko et al. (2014), OPFF in wet soil samples can reduce their mechanical properties. The result of this experiment is a confirmation to this and a pointer to the fact that OPFF is not a reliable soil reinforcement fibre. Attempting to use this for soil stabilisation would lead to undesirable behaviour, moreso the effect would be exacerbated with time because the fibre is biodegradable. It is recommended that application of OPFF as road material reinforcement should be confirmed after evaluation of its performance after chemical treatment. It can also be burnt to ash and be used as a pozzolanic stabilising material after a more extensive research based confirmation of its effectiveness. 


\section{Declarations}

\section{Availability of Data}

Relevant data has been presented in this paper.

\section{Funding}

Not applicable.

\section{Conflict of Interest}

The authors declare that there is no conflict of interest associated with this study.

\section{Author Contributions}

Chidozie Maduabuchukwu Nwakaire: Research administration, Writing - original draft, Supervision, data curation. Chidebele Evaristus Ukomadu: Investigation, Conceptualisation, Methodology. Chijioke Elijah Onu: Visualization, Writing - review \& editing.

\section{Acknowledgements}

Not applicable.

\section{References}

1. Anyaoha, K.E., Sakrabani, R., Patchigolla, K., MouazenA.M., (2018) Evaluating oil palm fresh fruit bunch processing in Nigeria. Waste Management Reseources, 0 (0), 1-11.

2. Federal Ministry of Works and Housing (FMWH) (1997) General specification for Roads and Bridges. volume 2, Federal Highway Department, FMWH: Lagos Nigeria.

3. Han, J. (2014). Recent research and development of ground column technologies. Proceedings of Institute of Civil Engineering.-Ground Improvement, 168 (4), 246-264.

4. Horpibulsuk, S., Rachan, R., Suddeepong, A. (2011) Assessment of strength development in blended cement admixed Bangkok clay. Construction and Building Materials, 25 (4), 1521-1531.

5. Ibitoye,S., Onje, S.O. (2013) Economic analysis of oil palm fruit processing in Dekina local government area of Kogi State, Nigeria. Academic Arena, 5 (11), 65-73.

6. Igwe, O., Umbugadu, A., A. (2020) Characterization of structural failures founded on soils in Panyam and some parts of Mangu, Central Nigeria. Geoenvironmental Disasters. 7(7). 
7. Jagustyn, B., Patyna, I., Skawińska, A. (2013) Evaluation of physicochemical properties of palm kernel shell as agro biomass used in the energy industry. Chemik, 67, 552-559.

8. Li, J., Ding, D. (2002) Nonlinear elastic behavior of fibre reinforced soil under cyclic loading. Soil dynamics and earthquake engineering, 138 (22), 977-983.

9. Mahato, D.N., Mathur, B.K., Bhattacherjee, S. (1993) Effect of Alkali Treatment on Thermal Stability and Moisture Retention of oil palm Fibre. Indian journal of Physics, 67(3), 251-272.

10. Mahmoud, H., Belel, Z.A, Nwakaire, C. (2012) Groundnut Shell Ash as a Partial Replacement of Cement in Sandcrete Blocks Production. International Journal of Development and Sustainability. 1(3). 1026-1032.

11. Nwakaire, C.M., Chukwu, J.C., and Udemba, J.N. (2016). Influence of Spatial Variation in Subgrade Properties on the Design of Highway Flexible Pavements. American Journal of Applied Scientific Research, 2 (6), 65-74.

12. Nwakaire, C.M., Nwaiwu, C.M.O., Aginam, C.H. (2015) Equivalent Blows Approach to the Calibration of a Minicompactor for Laboratory Use. IISTE Journal of Civil and Environmental Research, 7 (8), 6374.

13. Ossa, A., García, J. L., Botero, E. (2016). Use of recycled construction and demolition waste (CDW) aggregates: A sustainable alternative for the pavement construction industry. Journal of Cleaner Production, 135, 379-386.

14. Otoko G.R., Ephraim, M. (2014) Reinforcement of a Lateritic Soil Using Oil Palm Fruit Fibre. International Journal of Engineering and Technology Research, 2(6),1 - 5.

15. Otoko, G.R., Manuel, F.I., Ibekwe, S.C., Oyebode, J.O. (2016). Soft Soil Stabilization Using Palm Oil Fibre Ash. Journal of Multidisciplinary Engineering Science and Technology, 3(5), 4954-4958.

16. Plati, C. (2019) Sustainability factors in pavement materials, design, and preservation strategies: a literature review. Construction and Building Materials. 211, 539 - 555.

17. Rickson, R.J., Deeks, L.,K., Graves, A., Harris, J.A.H., Kibblewhite, M.G., Sakrabani, R. (2015) Input constraints to food production: the impact of soil degradation. Food Security. 7, 351-364.

18. Rowell, M., Han, S., Rowell, S. (2000). Characterization and factors effecting fibre properties. National Polymer Agro Composites, 52 (21), 115-34.

19. Sargent, P., Hughes, P.N., Rouainia, M. (2016) A new low carbon cementitious binder for tabilizing weak ground conditions through deep soil mixing. Soils Foundations, 56 (6), 1021-1034.

20. Sreekala, M.S; George, J., Kumaran, M.G., Thomas, S. (2001) Water absorption kinetics in oil palm fibre. Journal of Polymer Science, part B: Polymer Physics, 39 (11), 1215-1223.

21. Suroso, P. L., Samang, W., Tjaronge, W., Ramli, M. (2013) Palm Fibres Influence on the Compressive Strength and CBR of Soil Cement Proceedings of the $7^{\text {th }}$ International Conference on Asian and Pacific Coasts Bali, Indonesia, September 24-26.

22. Winter, M.G., Wong, J.C.F. (2020) The Assessment of Quantitative risk to road users from debris flow. Geoenvironmental Disasters. 7(4) 
23. Yao, K., Yao, Z., Song, X., Zhang, X., Hu, J., Pan, X. (2016) Settlement evaluation of soft ground reinforced by deep mixed columns. International Journal of Pavement Research Technology, 9 (6), 460-465.

24. Yusoff, M., Salit, M., Ismail, N., Wirawan, R. (2010) Mechanical properties of short random oil palm fibre reinforced epoxy composites. Sains Malay, 39, 87-92.

25. Zhang, M., Guo, H., El-Korchi, T., Zhang, G., Tao, M. (2013) Experimental feasibility study of geopolymer as the next-generation soil stabilizer. Construction and Building Materials, 47, 14681478.

\section{Figures}

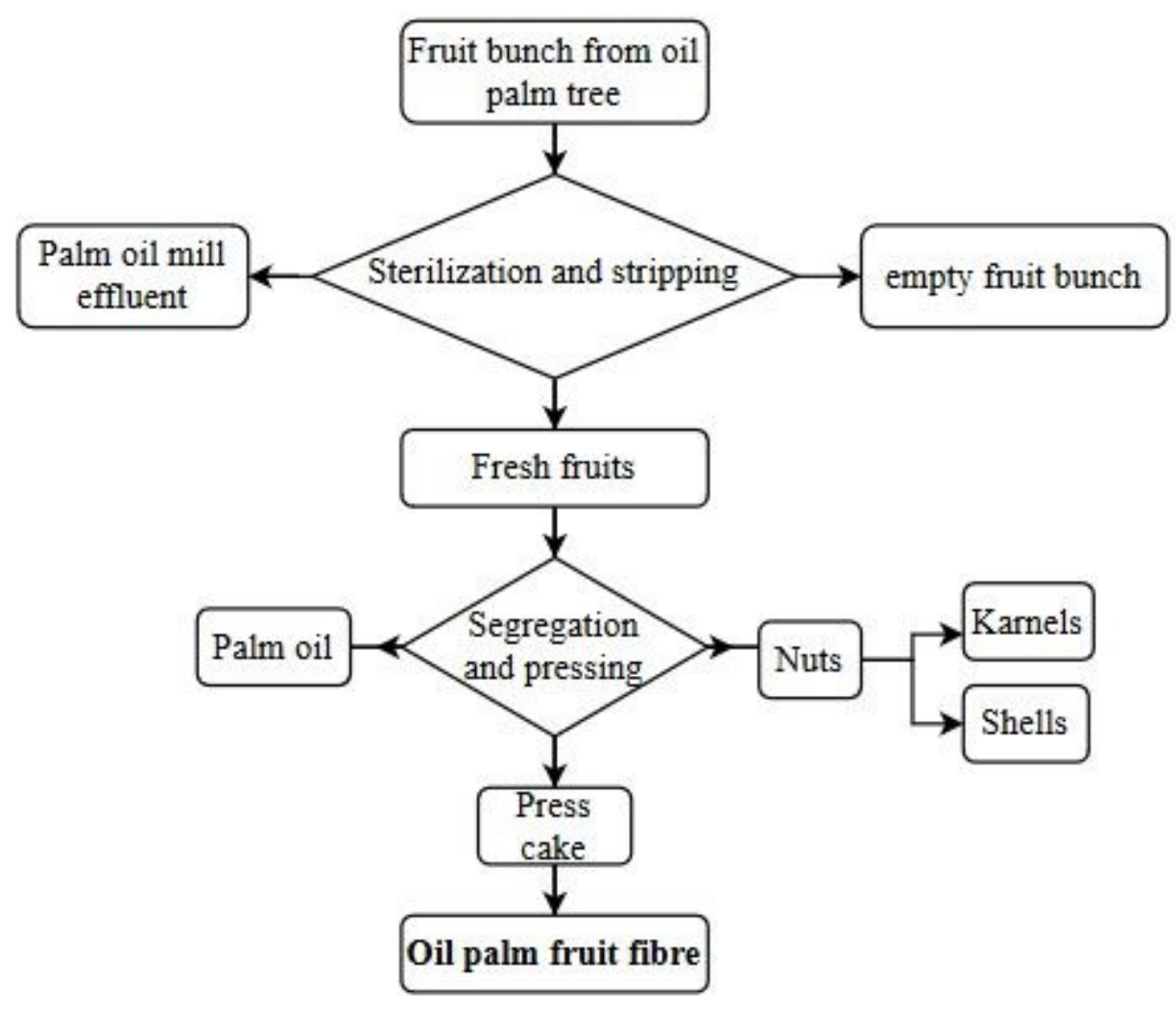

\section{Figure 1}

Flow chart showing palm oil processing and Production of Oil Palm Fruit Fibre 


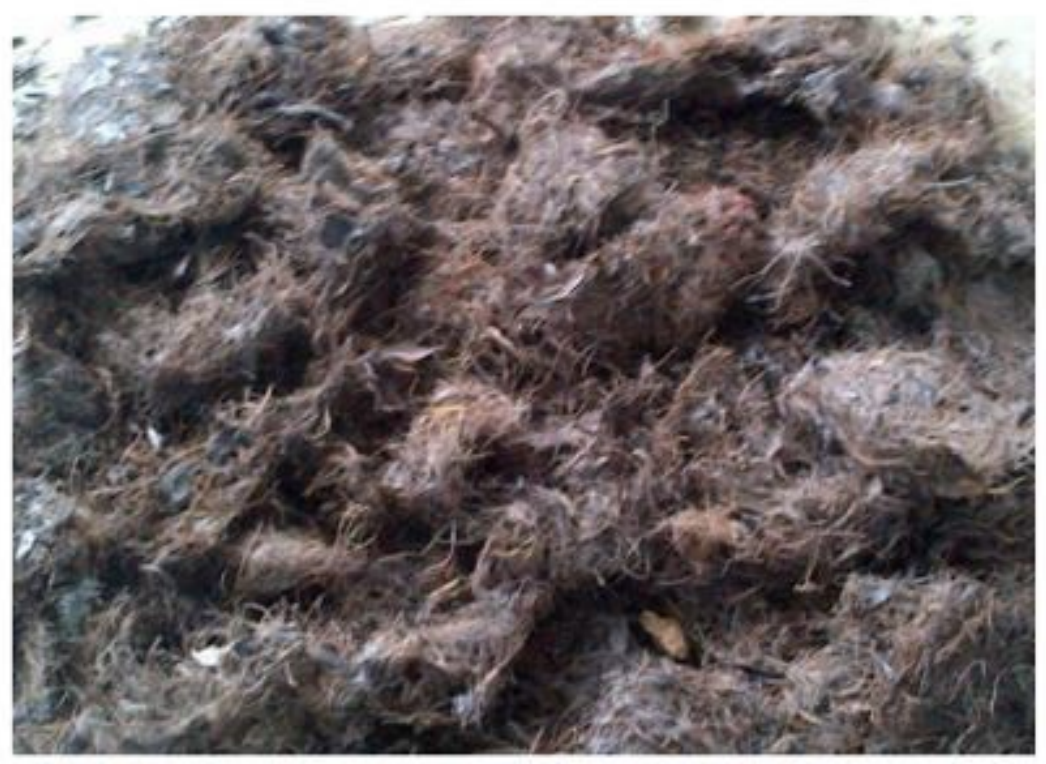

Figure 2

Oil palm fruit fibre

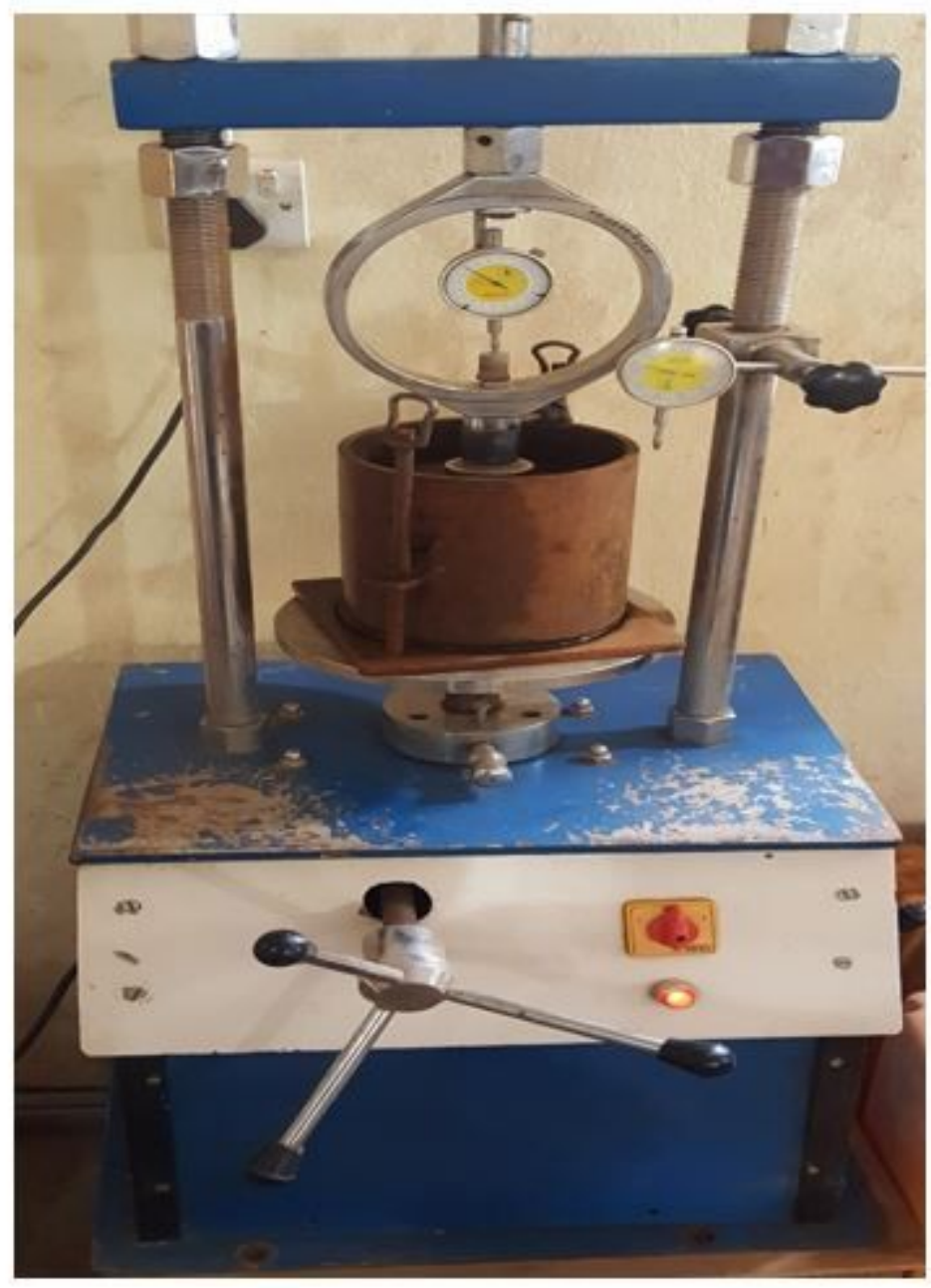


Figure 3

California Bearing Ratio Machine

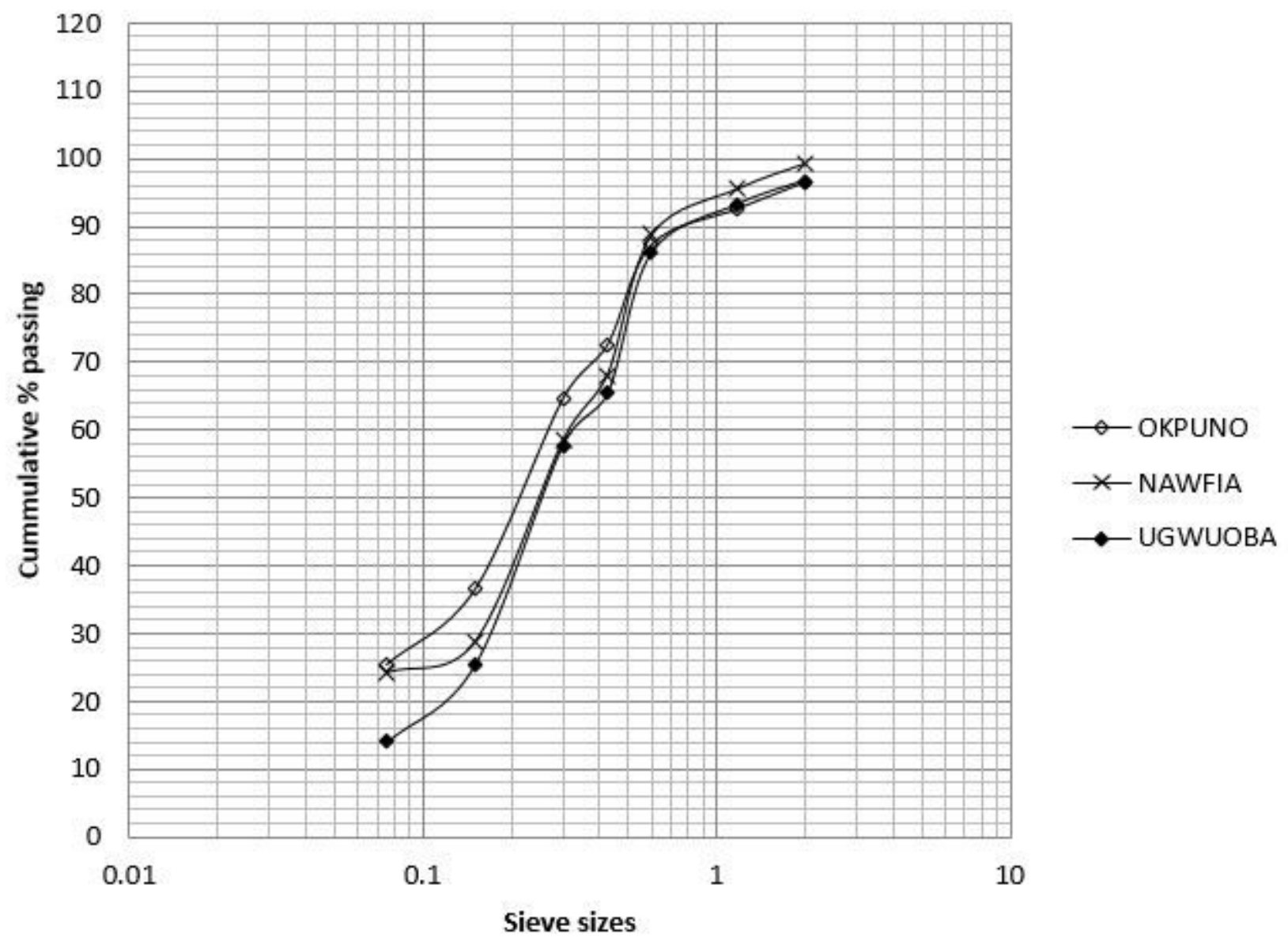

Figure 4

Particle size distribution of the three laterite samples 


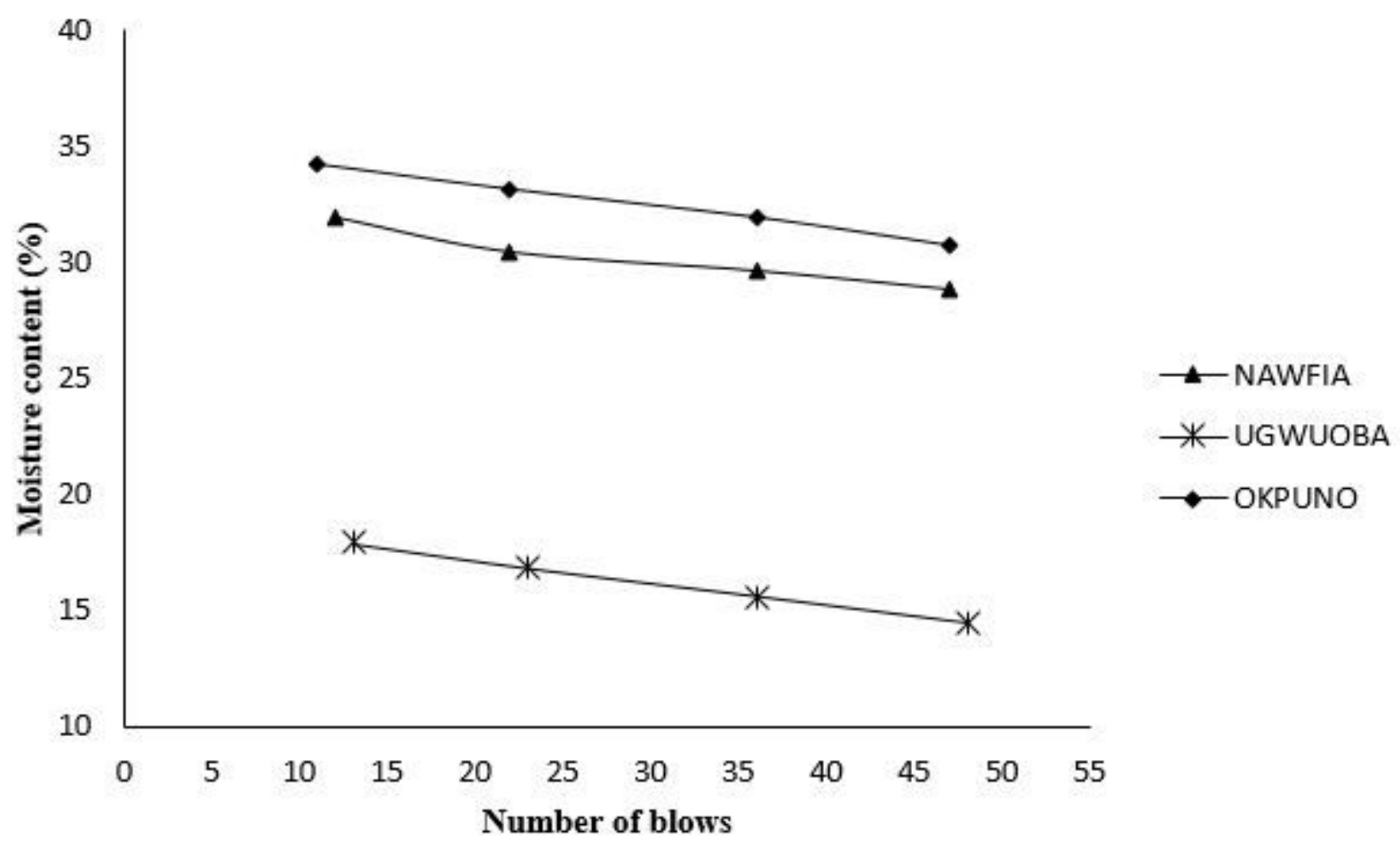

Figure 5

liquid limit plots for the soil samples

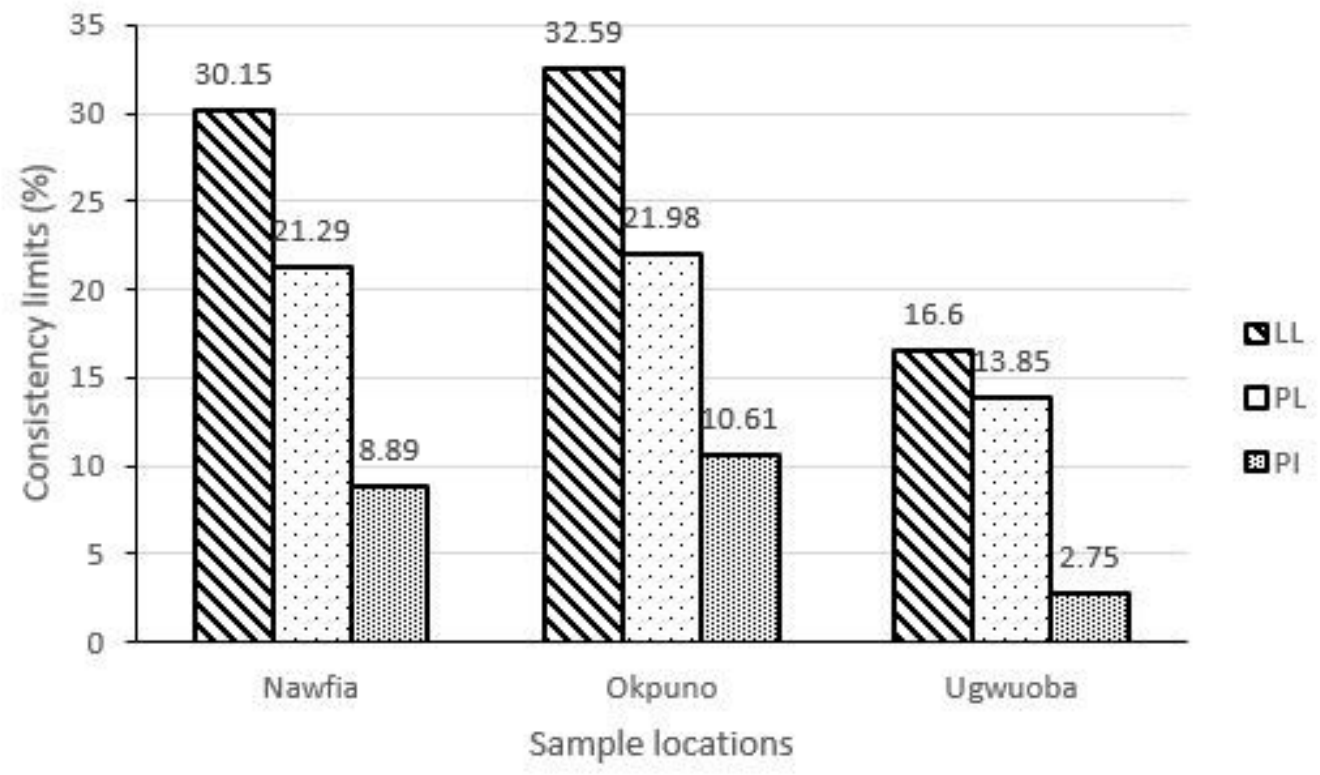

Figure 6

The consistency limits 


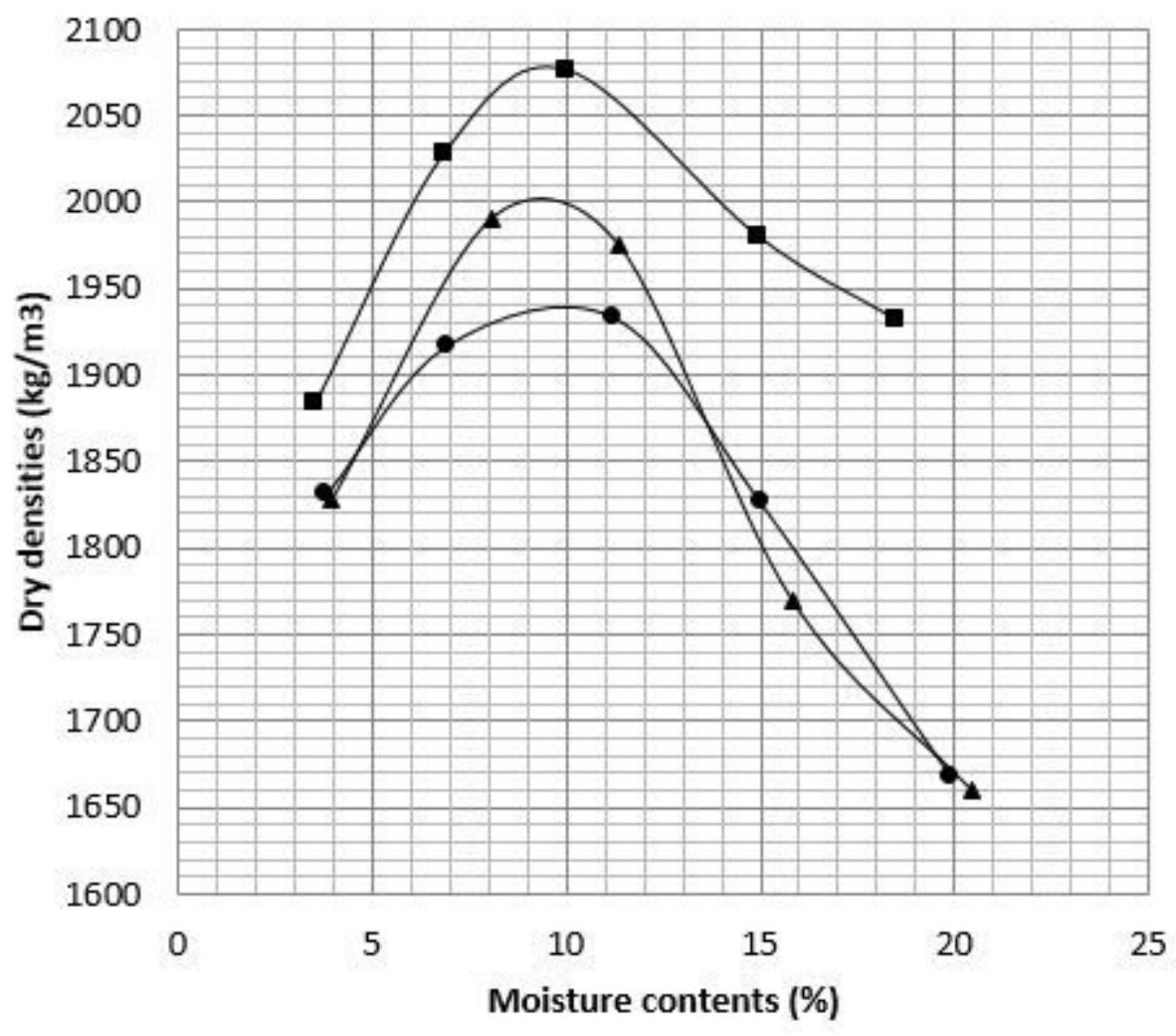

\section{$\rightarrow-$ BSH UGWUOBA \\ $₫$ WAS UgWUOBA \\ $\rightarrow$ BSL UgWUOBA}

\section{Figure 7}

Compaction curves for Ugwuoba soil sample

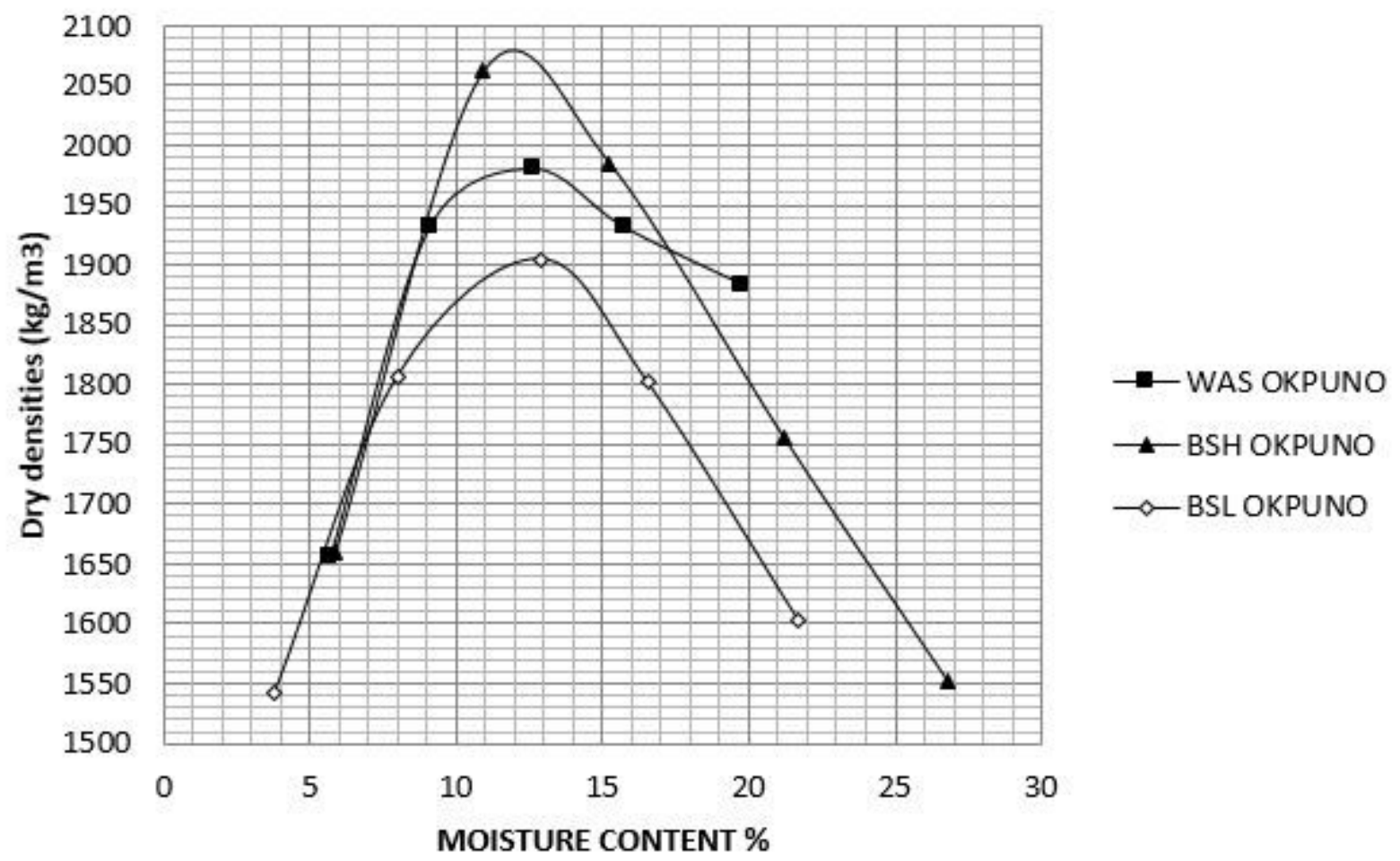


Figure 8

Compaction curves for Okpuno soil sample

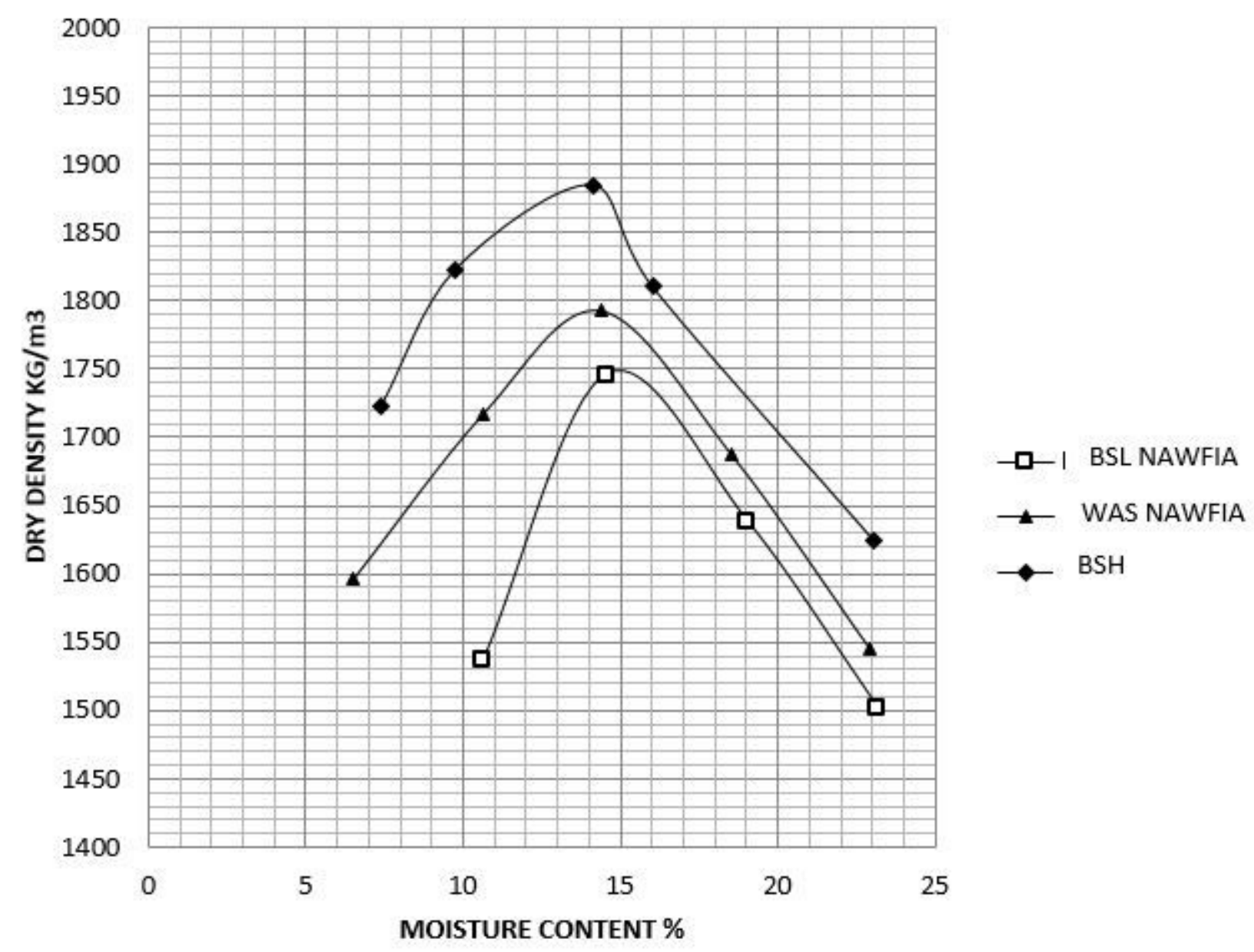

Figure 9

Compaction curves for Nawfia soil sample 


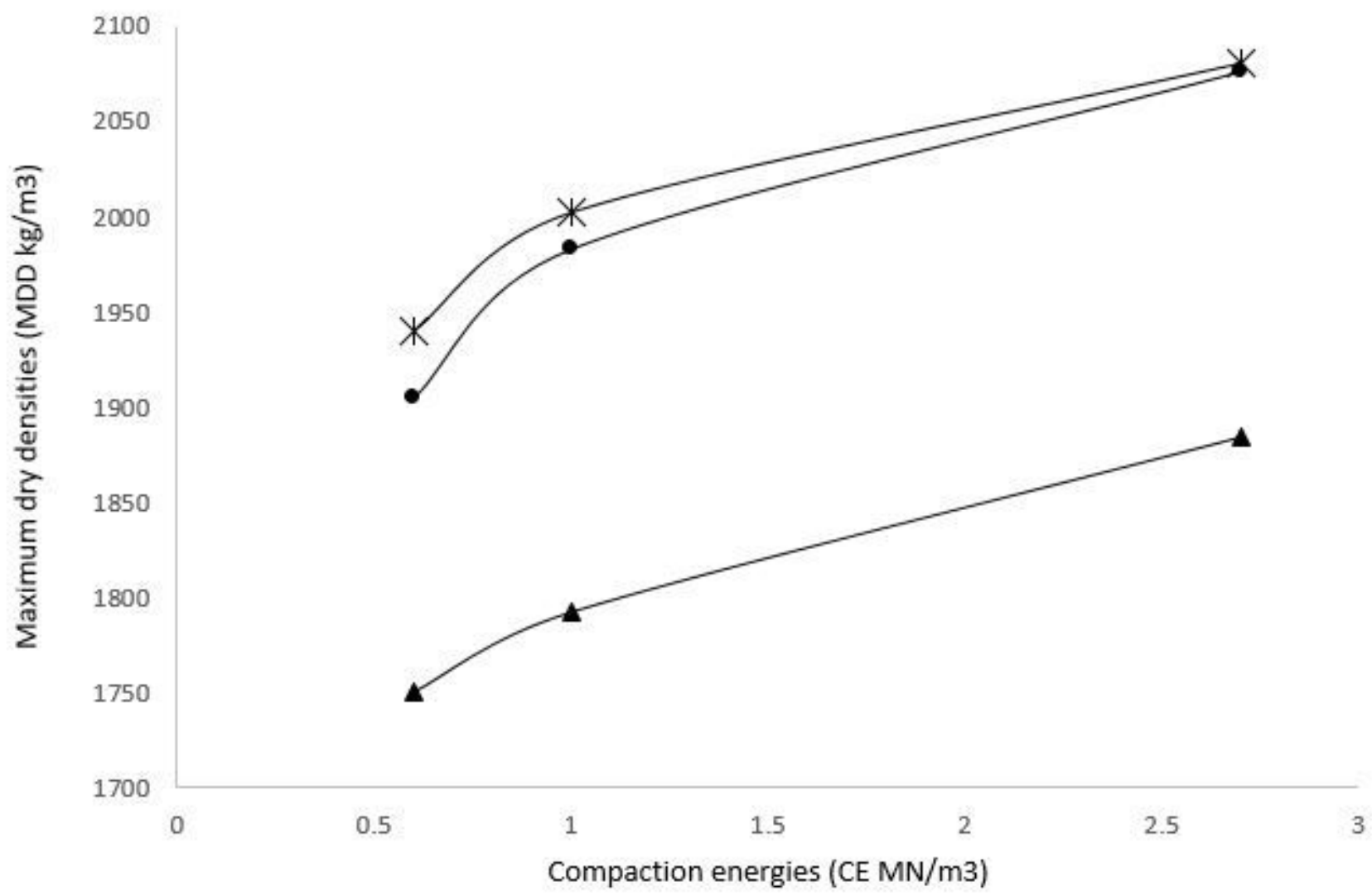

Figure 10

Influence of compaction energy on MDD 


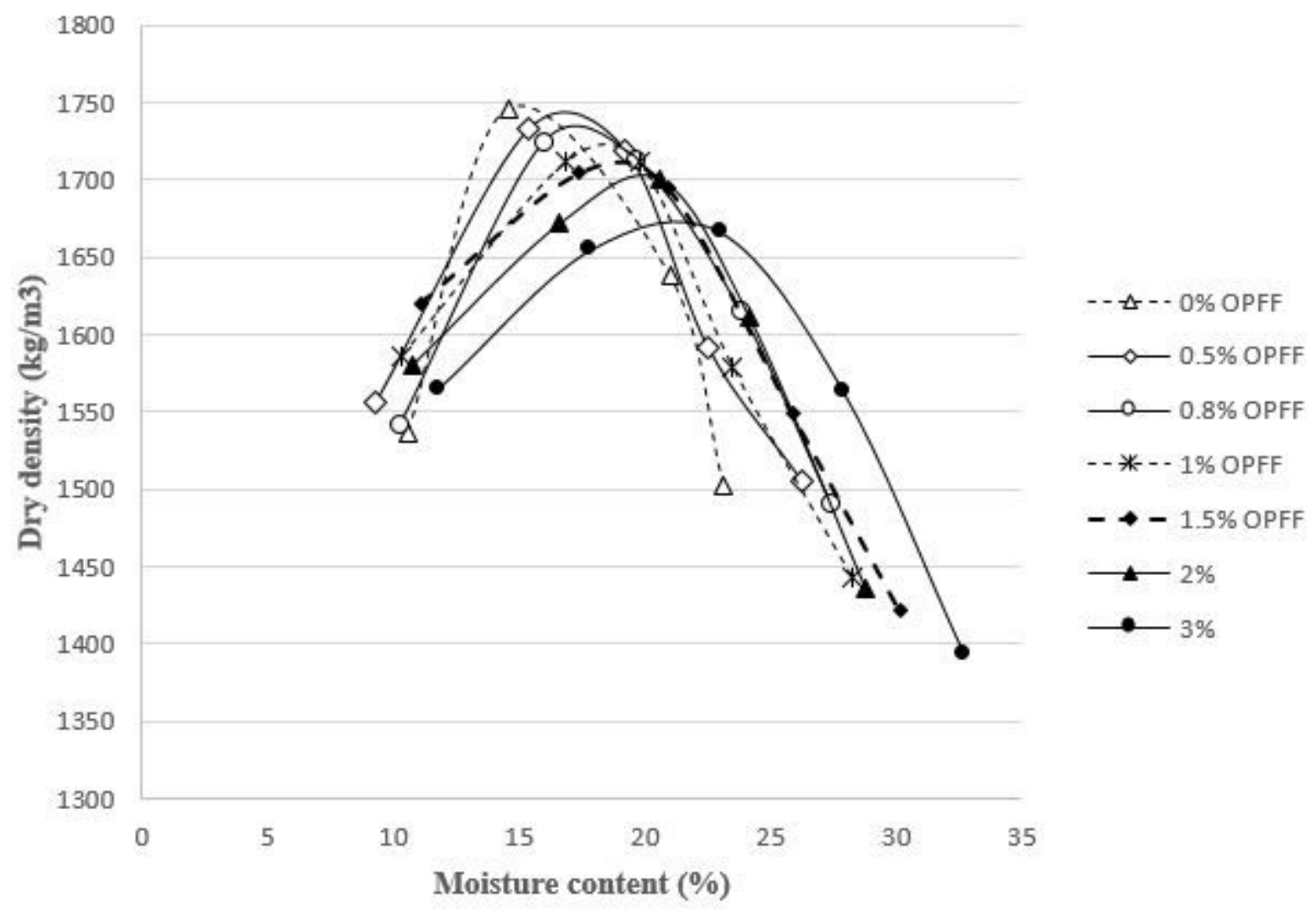

Figure 11

Compaction curve for OPFF in Nawfia laterite 


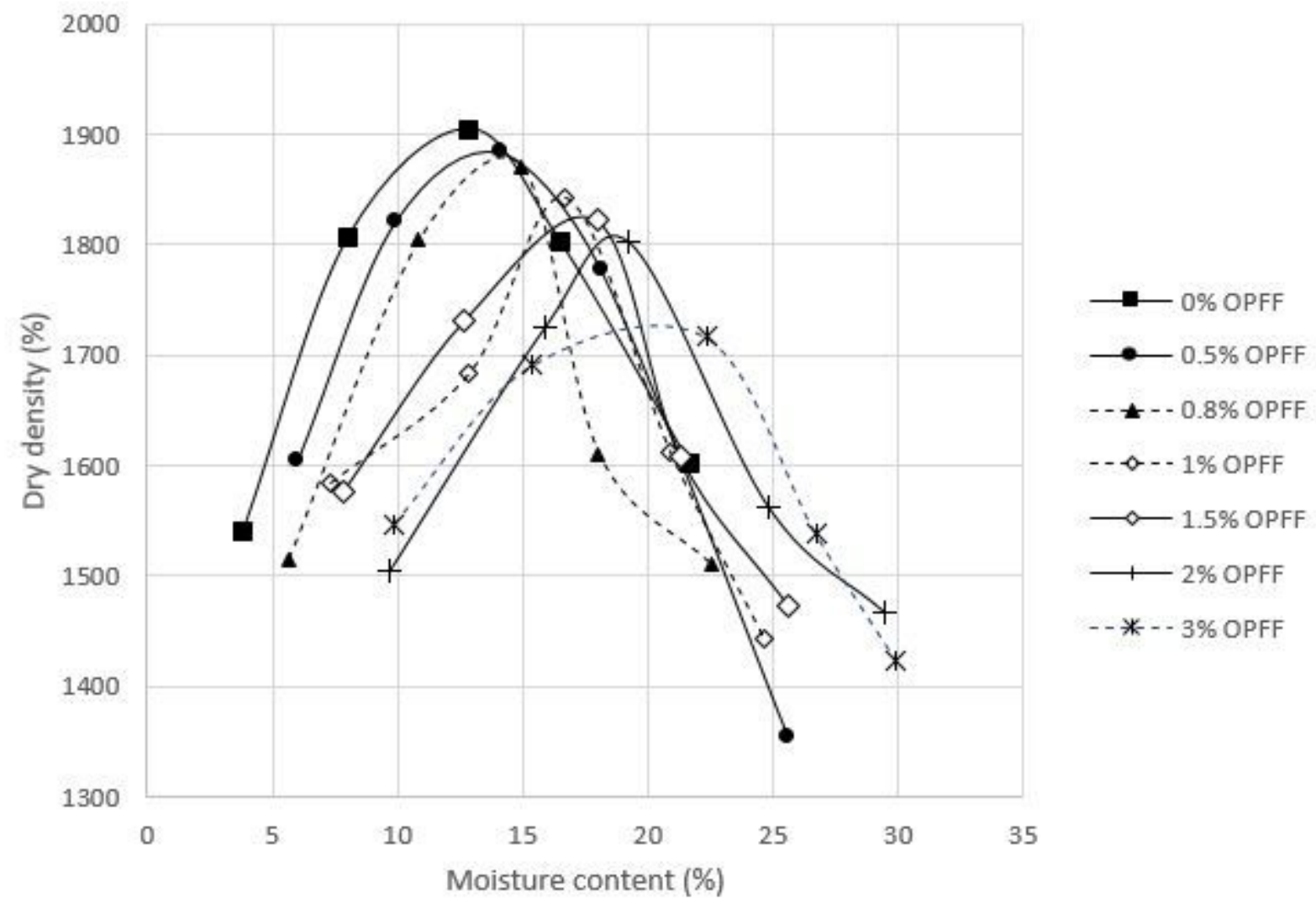

Figure 12

Compaction curve for OPFF in Okpuno laterite 


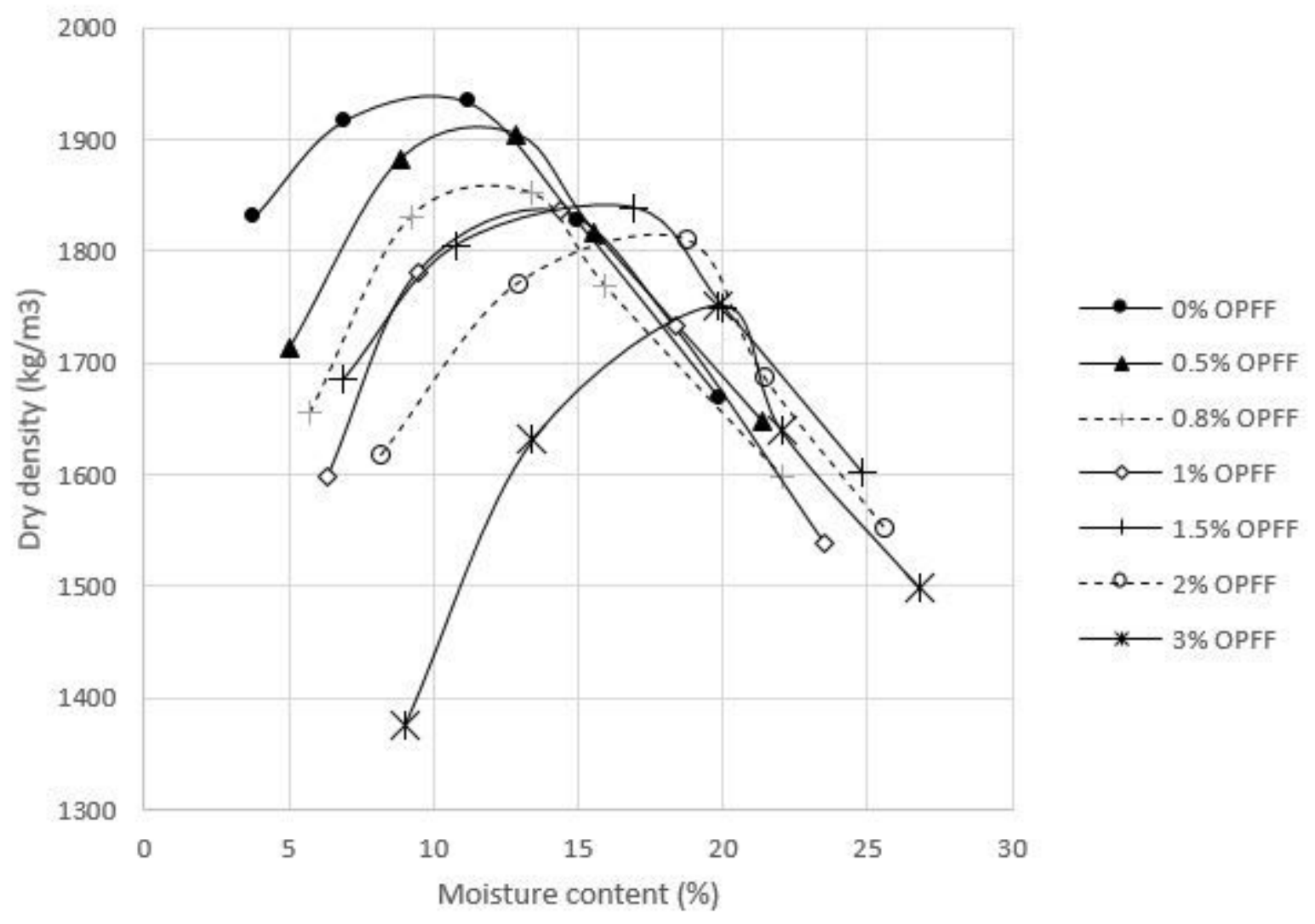

Figure 13

Compaction curve for OPFF in Ugwuoba laterite

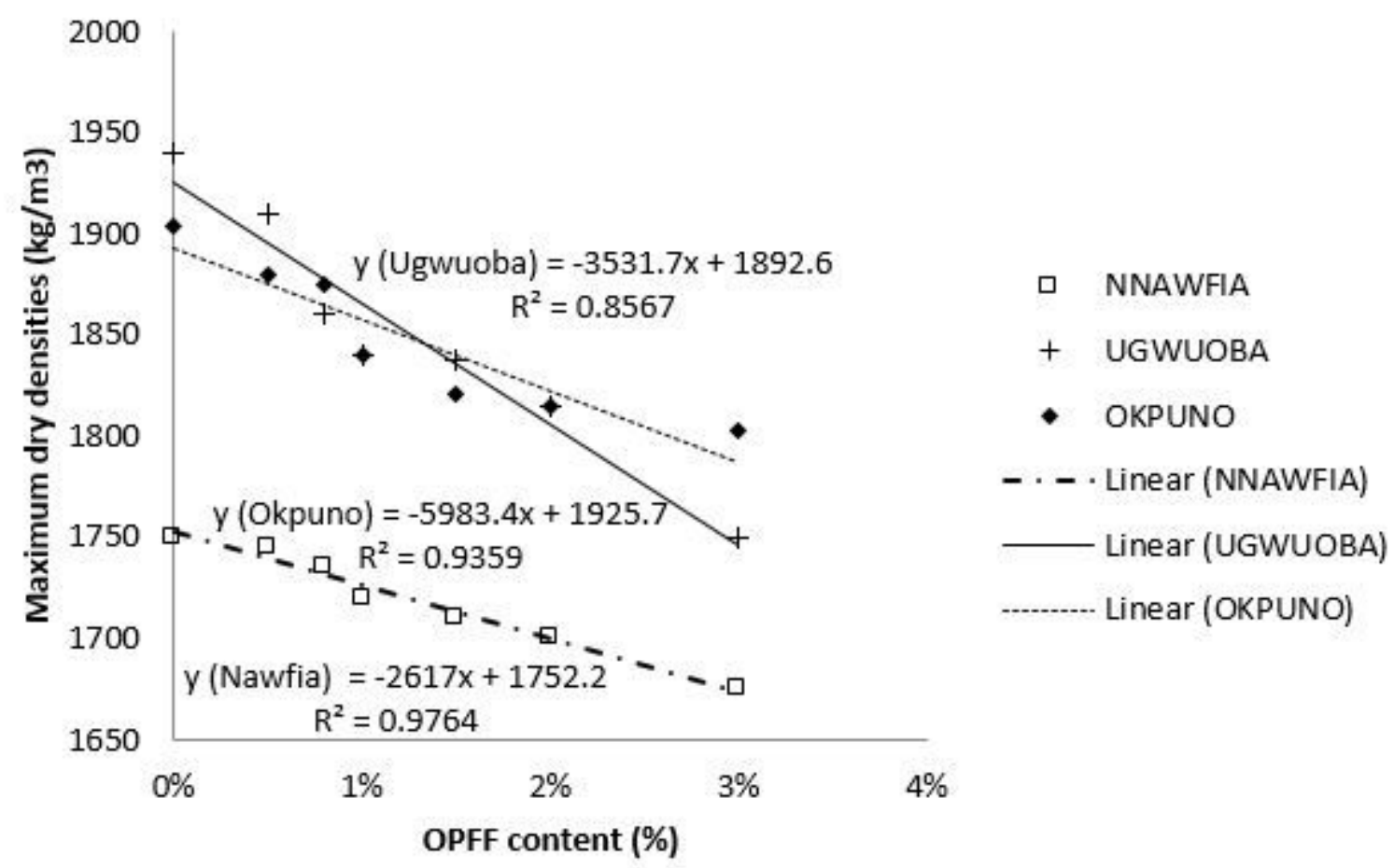


Figure 14

Reduction in MDD with increase in OPFF

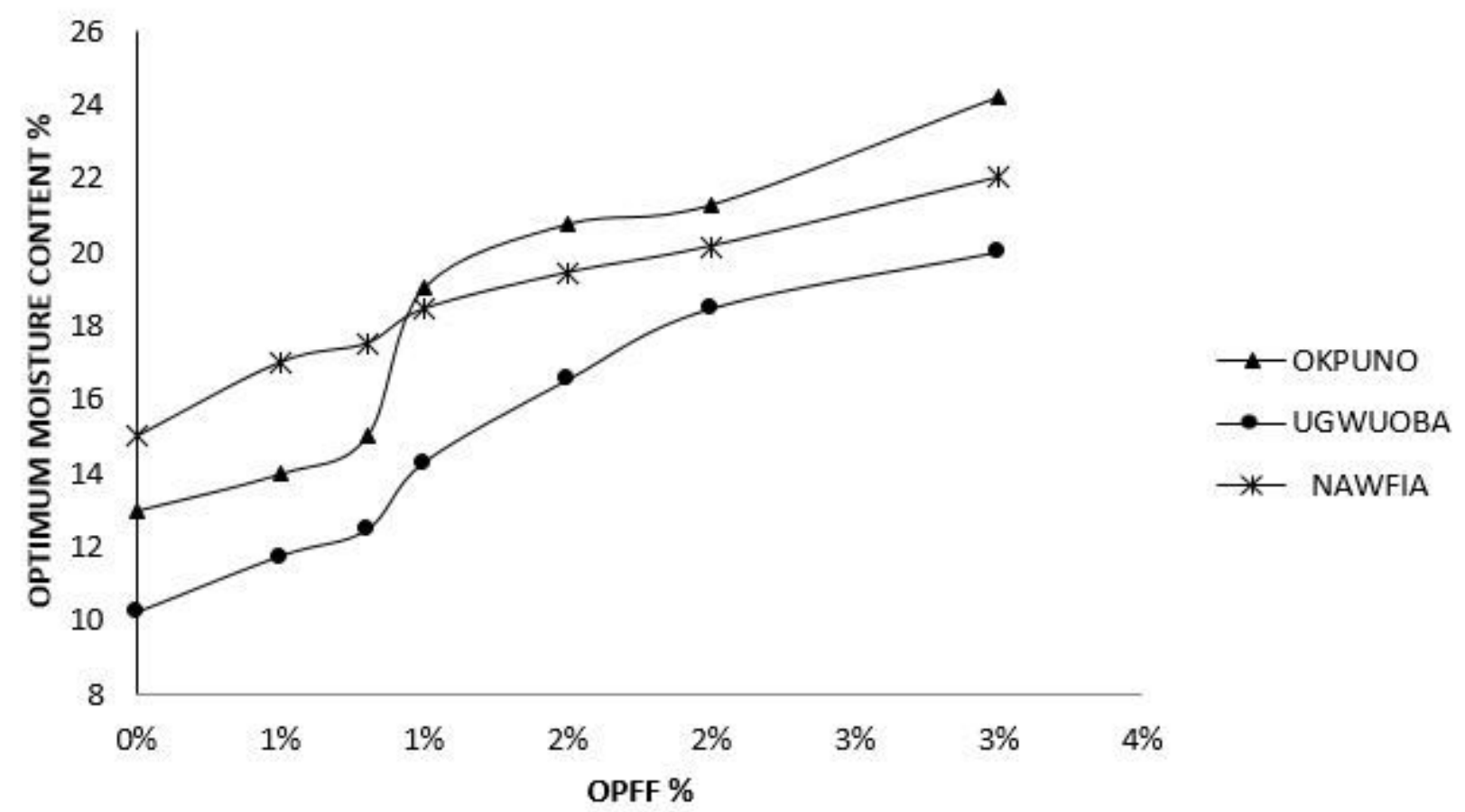

Figure 15

Increase in OMC with increase in OPFF

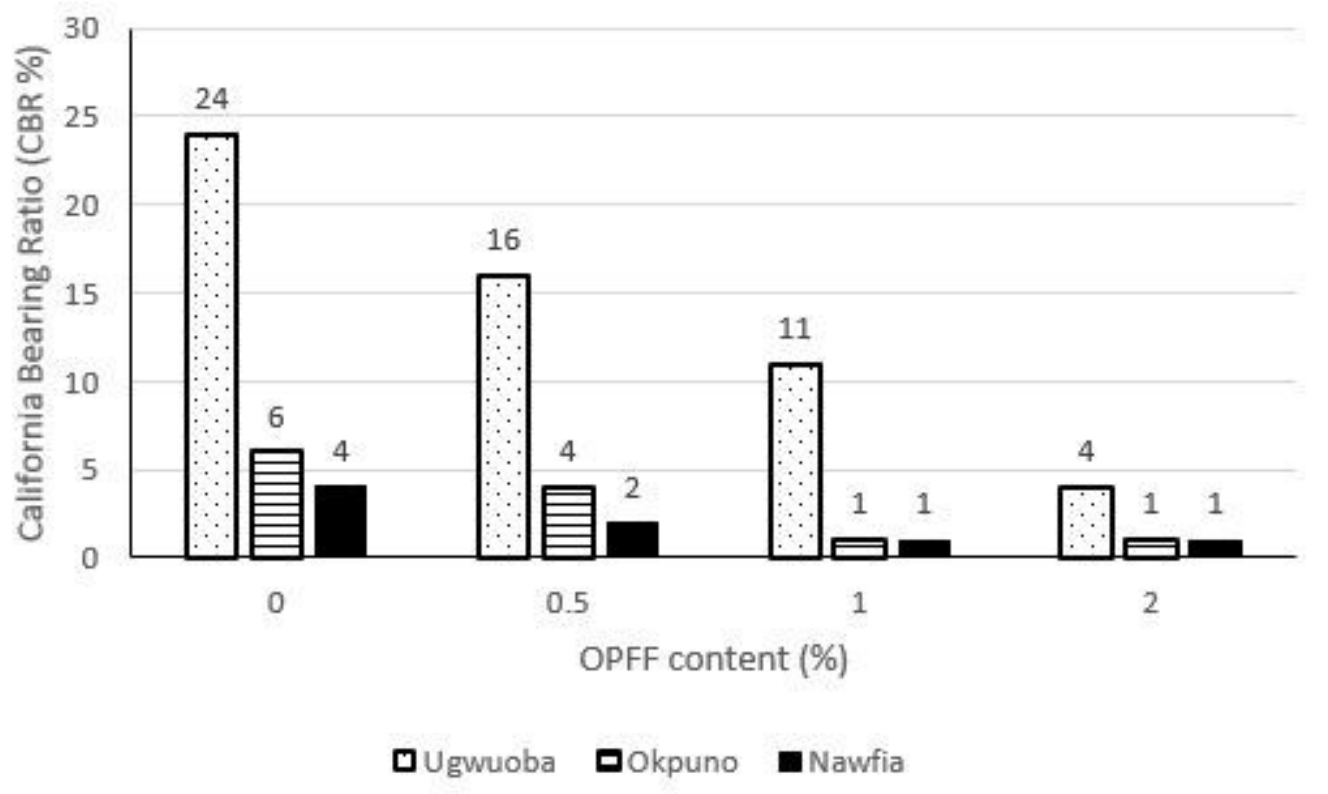

Figure 16

Result of CBR with OPFF inclusion 